\title{
Importance of Clinical Suspicion in Rapid Diagnostic Test Negativity in Malaria: Two Case Reports
}

Cem Gun ${ }^{1}$, Hasan Aldinc ${ }^{1}$, Serpil Yaylaci' ${ }^{1}$, Cemal Ustun², Erol Barbur ${ }^{3}$

${ }^{1}$ Acibadem Mehmet Ali Aydinlar University, School of Medicine, Department of Emergency Medicine, Istanbul ${ }^{2}$ Hasan Kalyoncu University, Institute of Health Sciences, Gaziantep

${ }^{3}$ Acibadem Mehmet Ali Aydinlar University, School of Medicine, Istanbul

\begin{abstract}
Introduction: Malaria is a life-threatening disease caused by infection with Plasmodium parasites. Rapid diagnostic tests (RDTs) have been used for the diagnosis of malaria without special equipment by unskilled personnel over the last 15 years. The treatment should only be given after the clinical diagnosis confirmed by RDT or microscopy. RDTs' specificity and sensitivity have been reported as $>95 \%$ by the World Health Organization - Foundation for Initiative New Diagnostics (WHO-FIND).
\end{abstract}

Case report: A 30-years-old male and a 23-years-old female presented to our emergency department with fever and history of a visit to a malaria-endemic country. Plasmodium trophozoites were seen in the blood smear samples via light microscopy. However, RDTs were negative. The patients were treated according to their pathogens.

Conclusion: Rarely, RDT might result in a false negative in the diagnosis of malaria. People travelling to endemic areas should be closely monitored. Emergency department physicians should not neglect microscopy which is the gold standard for diagnosis of malaria.

Keywords: Clinical Microbiology; Emergency Departments; Infectious Diseases; Parasitology; Plasmodium

\section{Introduction}

Malaria is one of the most common reasons to seek medical care and associated with considerable morbidity and mortality in many sub-Saharan countries. Africa has the greatest malaria burden, with $91 \%$ of malaria-related deaths worldwide ${ }^{1}$. Plasmodium parasites cause acute febrile diseases, ranging from 6 to 30 days after transmission. Among them, Plasmodium. falciparum is the most severe form of malaria and is responsible for more than $80 \%$ of the deaths worldwide ${ }^{2}$. Currently, the routinely used parasitological tests are microscopy and rapid diagnostic test (RDT). Light microscopy with the application of Giemsa stain is the "gold standard" for laboratory diagnosis of malaria, however, during the last World Health Organization - Foundation for Initiative New Diagnostics (WHO-FIND) reported high sensitivity ( $>95 \%$ ) regarding P. falciparum detection of RDTs ${ }^{3,4}$.

In this paper, we describe two cases of patients with $P$. falciparum and $P$. vivax infections found on light microscopy, but for whom the RDTs were negative.

\section{Case 1}

A 30-years-old male presented to the Emergency Department (ED) of our university hospital in Turkey with a history of fever, productive cough and sore throat persisting for two days. The patient stated that his body temperature suddenly escalates during sleep, his fever had been more apparent at night. There was no remarkable illness or medication in the patient's medical history. His physical examination showed as follows: a body temperature of $38.7^{\circ} \mathrm{C}$, blood pressure of $110 / 63 \mathrm{mmHg}$, heart rate of 92 beats per minute, respiratory rate of 17 per minute, and pulse oximetry of $99 \%$ in room air, severe oropharyngeal hyperaemia, and postnasal drip. Laboratory findings were as follows: haemoglobin, $15,9 \mathrm{~g} /$ $\mathrm{dL}$; white blood cell count, $4,6 \times 10^{3} / \mu \mathrm{L}$; platelet count, $17,1 \times 10^{3} / \mu \mathrm{L}$; blood urea nitrogen, $18 \mathrm{mg} / \mathrm{dL}$; creatinine, $1,01 \mathrm{mg} / \mathrm{dL}$; and the chest radiograph was normal. He lives in Turkey where is not one of the malaria-endemic countries. It was learned that he had been in a malaria-endemic country twice in the last month for 2 days but had no insect bite history. First, an RDT was planned for malaria screen- 
ing. It was negative (Figure 1). Considering the findings above, he was evaluated as an upper airway infection and discharged with a prescription. The next day he presented to the ED with fever $\left(39.1^{\circ} \mathrm{C}\right)$ and diffuse muscular pain. Physical examination and laboratory tests were similar with first results except for platelet count (Platelet count: 5,3 $\times$ $\left.10^{4} / \mu \mathrm{L}\right)$. Because of the development of thrombocytopenia, an infectious diseases physician was consulted. RDT was repeated and Giemsa painted thick and thin smears were ordered additionally. RDT resulted before microscopy and it was negative again. In contrast with RDT, $P$. falciparum was detected under microscopy (Figure 2) and the patient was started with the treatment immediately. The patient was started on treatment with artemether-lumefantrine combination therapy for three days, according to WHO recommendations (Table 1). The patient fully recovered after this treatment. Clinical and laboratory examination of the patient was found as normal after 15 days of discharge.

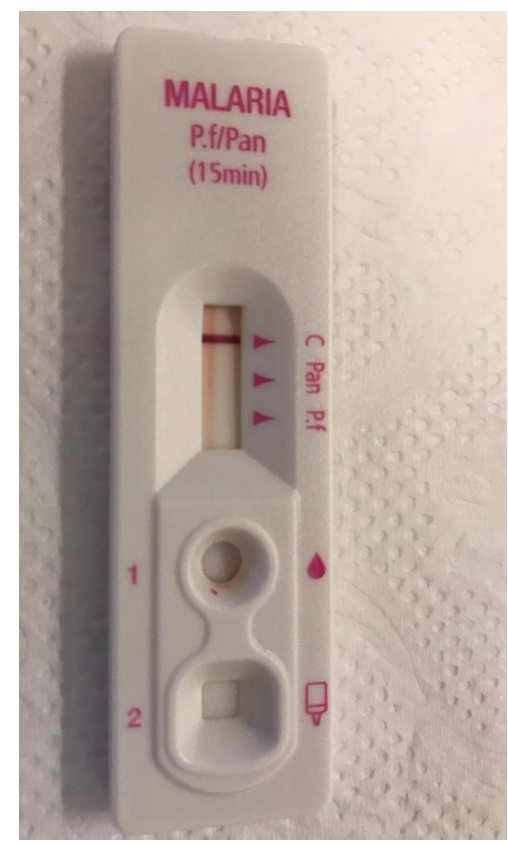

Figure 1: Negative rapid diagnostic test (only the control line is seen).

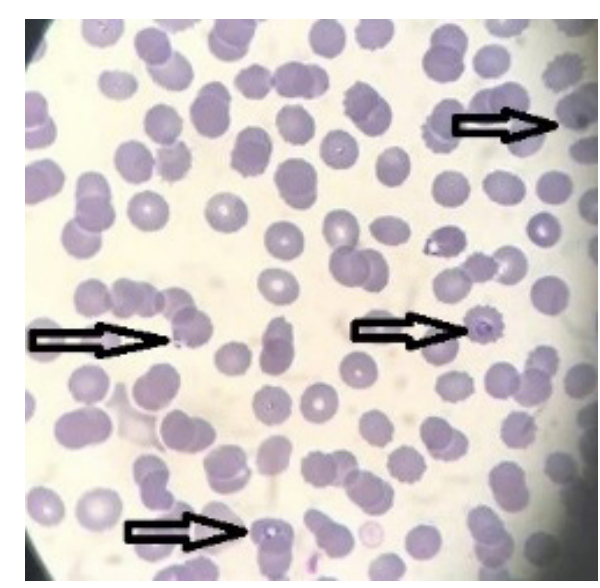

Figure 2: Blood smear microscopy shows Plasmodium falciparum parasites (arrows) infecting the patient's red blood cells (Giemsa stain, x100 magnification).
Table 1. Artemether-lumefantrine based combination therapy doses (tb: tablet)

\begin{tabular}{cccccc}
\hline $\begin{array}{c}\text { Patient } \\
\text { Weight }(\mathrm{kg})\end{array}$ & $\begin{array}{c}\text { First } \\
\text { Dose }\end{array}$ & $\begin{array}{c}8^{\text {th }} \\
\text { Hour }\end{array}$ & $\begin{array}{c}24^{\text {th }} \\
\text { Hour }\end{array}$ & $\begin{array}{c}36^{\text {th }} \\
\text { Hour }\end{array}$ & $\begin{array}{c}48^{\text {th }} \\
\text { Hour }\end{array}$ \\
\hline$<15$ & $1 \mathrm{tb}$ & $1 \mathrm{tb}$ & $1 \mathrm{tb}$ & $1 \mathrm{tb}$ & $1 \mathrm{tb}$ \\
\hline $15-24$ & $2 \mathrm{tb}$ & $2 \mathrm{tb}$ & $2 \mathrm{tb}$ & $2 \mathrm{tb}$ & $2 \mathrm{tb}$ \\
\hline $25-34$ & $3 \mathrm{tb}$ & $3 \mathrm{tb}$ & $3 \mathrm{tb}$ & $3 \mathrm{tb}$ & $3 \mathrm{tb}$ \\
\hline$>34$ & $4 \mathrm{tb}$ & $4 \mathrm{tb}$ & $4 \mathrm{tb}$ & $4 \mathrm{tb}$ & $4 \mathrm{tb}$ \\
\hline
\end{tabular}

\section{Case 2}

A 23-years-old female presented to the ED of our university hospital in Turkey with an insect bite lesion and a history of fever for the past three days. She stated that she was in Africa, an endemic country for malaria, for 48 hours, 18 days before her application. It was learnt that she has been experiencing periodic fevers. Her physical examination showed as follows: a body temperature of $38,6^{\circ} \mathrm{C}$, blood pressure of $100 / 60 \mathrm{mmHg}$, heart rate of 90 beats per minute, respiratory rate of 20 per minute, and pulse oximetry of $100 \%$ in room air. Laboratory findings were as follows: haemoglobin, 13,2 $\mathrm{g} / \mathrm{dL}$; white blood cell count, $3,85 \times 10^{3} / \mu \mathrm{L}$; platelet count, $99 \times 10^{3} / \mu \mathrm{L}$; blood urea nitrogen, $3 \mathrm{mg} / \mathrm{dL}$; creatinine, 0,55 $\mathrm{mg} / \mathrm{dL}$; and the chest radiograph was normal. Abdominal ultrasonography did not detect hepatosplenomegaly. RDT and microscopy from the blood sample obtained through antecubital cannulation planned for malaria screening and resulted as negative. The patient left the hospital to travel and was strongly advised to apply to an infectious diseases specialist in another city. She presented to another university hospital on her $4^{\text {th }}$ day of fever. When infectious diseases department of the university was contacted, it was reported that the microscopy test from the blood sample obtained from patient's fingertip revealed $P$. vivax, but RDT was still negative. The patient was treated with artemether-lumefantrine based combination therapy were used for 3 days and primaquine for 14 days. Patient full recovered after this treatment and was discharged from the hospital. Clinical and laboratory examination of the patient was found as normal after 15 days of discharge.

\section{Discussion}

These cases focus on two malaria diagnostics (microscopy and RDT) that are likely to have the largest impact on malaria control. In many countries sub-Saharan Africa, an electricity supply is not available in villages, thus hampering the use of microscopy for malaria diagnosis which needs a reliable electricity supply. RDTs are used as an alternative in those locations. RDTs have a specificity problem and may result in a significant number of false-positive test results 
when compared with the golden standard, expert microscopy. RDTs were false-negative in our cases, which were performed on the second and third days of the fever. The false negativity of RDT may be explained by the following reasons: The first, the occurrence of deletion or mutation on the histidine-rich protein 2 gene ${ }^{5}$. Second, the presence of an inhibitor in patient's blood preventing the development of the control line ${ }^{6}$. The last, lower parasite densities may lead to the false negativity of $\mathrm{RDT}^{7}$. According to the literature, most false-negative results of RDTs occur at lower parasite densities. RDTs have demonstrated sensitivities approximate to $100 \%$ for the detection of $P$. falciparum at densities above 100 asexual parasites $/ \mu \mathrm{L}$ or $>0.002 \%$ of parasitized red blood cells ${ }^{8}$.

Experienced microscopists, increased examination time and the number of microscopic fields examined could facilitate the identification of Plasmodium species correctly. However, in health facilities with a high workload, the use of microscopy alone is not recommended since it requires more time to perform than an RDT. Health workers with poor supervision or inadequate training should preferably use RDTs which are comparatively easier to use than a microscope. Each of these two parasitological tests has its strengths and weaknesses for an accurate diagnosis of malaria ${ }^{4}$. Therefore, WHO recommends that both tests should be performed for the diagnosis of malaria in the clinical applications.

Prompt and accurate diagnosis will not only improve malaria treatment but also possibly reduce mortality and morbidity due to other febrile illnesses, however, malaria diagnosis is the most neglected area of malaria research in 2004, accounting for less than $0.25 \%$ (\$700.000) of the United States of America's \$323 million investment in research and development ${ }^{9}$.

In developed countries, RDTs can be useful in screening febrile returnees from endemic areas. People travelling for touristic or work-related purposes to the endemic areas must be monitored closely ${ }^{10}$.

\section{Conclusion}

Physicians should not forget that RDTs might provide false negative results. Both microscopy and RDTs should be performed for diagnosis of malaria. Presence of fever and a history of travel to an endemic region in the last 30 days, regardless of the duration of the stay nor the existence of a bite lesion, must be considered highly suspicious for infection.
Combining RDTs and microscopy holds great importance in the accurate diagnosis and treatment.

\section{References}

1. World Health Organization. World Malaria Day 2018: Ready to beat malaria. WHO Media; 2018. https://www.who.int/malaria/media/world-malaria-day-2018/en/ [accessed 04 August 2020]

2. Gardner MJ, Hall N, Fung E, White O, Berriman M, Hyman RW, et al. Genome sequence of the human malaria parasite Plasmodium falciparum. Nature 2002; 419: 498-511. https:// doi.org/10.1038/nature01097

3. World Health Organization. New perspectives: malaria diagnosis: report of a joint WHO/USAID informal consultation, 25-27 October 1999 https://apps.who.int/iris/handle/10665/66321 [accessed 04 August 2020]

4. World Health Organization. Malaria rapid diagnostic test performance: results of WHO product testing of malaria RDTs: Round 6 (2014-2015). Geneva: World Health Organization; 2015. https://www.who.int/malaria/publications/ atoz/9789241510035/en/ [accessed 04 August 2020]

5. Wellems TE, Walker-Jonah A, Panton LJ. Genetic mapping of the chloroquine-resistance locus on Plasmodium falciparum chromosome 7. Proc Natl Acad Sci U S A 1991; 88: 3382-6. https://doi.org/10.1073/pnas.88.8.3382

6. Durand F, Faure O, Brion JP, Pelloux H. Invalid result of Plasmodium falciparum malaria detection with the BinaxNOW Malaria rapid diagnostic test [2]. J Med Microbiol 2005; 54: 1115. https://doi.org/10.1099/jmm.0.46067-0

7. Maguire JD, Lederman ER, Barcus MJ, O’Meara WA, Jordon RG, Duong S, et al. Production and validation of durable, high quality standardized malaria microscopy slides for teaching, testing and quality assurance during an era of declining diagnostic proficiency. Malar J 2006; 5: 92. https://doi. org/10.1186/1475-2875-5-92

8. Murray CK, Gasser RA, Magill AJ, Miller RS. Update on rapid diagnostic testing for malaria. Clin Microbiol Rev 2008; 21: 97-110. https://doi.org/10.1128/cmr.00035-07

9. Malaria R\&D Alliance. Malaria Research \& Development Alliance. An Assessment of Global Investment. November 2005. https://www.mmv.org/newsroom/publications/malaria-research-development-assessment-global-investment [accessed 04 August 2020]

10. Farag E, Bansal D, Chehab MAH, et al. Epidemiology of malaria in the state of Qatar, 2008-2015. Mediterr J Hematol Infect Dis 2018; 10: e2018050. https://doi.org/10.4084/ mjhid.2018.050 